ARTIGOS

\title{
REFLETINDO SOBRE A OBJETIVIDADE: UMA EXPERIÊNCIA DIDÁTICA SOBRE O POSITIVISMO DE COMTE
}

Leonel Gois Lima Oliveira leonelgois@gmail.com Doutor em Administração. Professor da Escola Superior de Magistratura do Estado do Ceará (ESMEC) Fortaleza-CE-BR.

Carlos Eduardo Franco Azevedo francoazevedo@globo.com Doutor em Administração. Coronel de Engenharia do Exército. Professor vinculado à Escola de Comando e Estado Maior do Exército-Rio de Janeiro - RJ-BR.

Rafael Kuramoto Gonzalez rafael_k_gonzalez@yahoo.com.br Doutor em Administração. Professor da Universidade Tecnológica Federal do Paraná-Pato Branco - PR - BRDAADM/UTFPR.

Márcio Moutinho Abdalla marciomabdalla@id.uff.br Doutor em Administração. Professor da Universidade Federal Fluminense-Volta Redonda-RJ$B R-P P G A-M P A$..

\section{RESUMO}

O positivismo surgiu como uma das primeiras correntes de pensamento sistematizada reconhecida como uma epistemologia em ciências sociais. Buscou-se sistematizar uma forma de estudo da epistemologia positivista, propiciando um melhor aproveitamento didático-pedagógico dos estudantes. $\mathrm{O}$ estudo empírico realizou-se a partir de uma abordagem qualitativa, relatando uma experiência didática, na forma de oficina, a qual serviu como caso a ser estudado, pois, neste ambiente, pode-se interagir com doutorandos do curso de Administração. Por meio deste relato, debateu-se acerca dos principais conceitos da epistemologia positivista e forneceram-se insumos didático-pedagógicos àqueles que desejam explorar encontros sobre esta temática nos níveis de graduação ou pós-graduação.

Palavras-chave: Ensino. Pós-Graduação. Positivismo. Epistemologia. Administração.

\section{INTRODUÇÃO}

O paradigma positivista foi uma das primeiras correntes de pensamento sistematizada, reconhecida como uma epistemologia em ciências sociais. Segundo Costa (2005), fora a primeira a estabelecer, precisamente, o objeto de investigação, a direcionar métodos e a definir conceitos. Em linhas gerais, o positivismo, segundo Abbragnano (1970), é um termo que caracteriza epistemologias que buscam explicar e predizer acontecimentos do mundo social, buscando causalidades. De acordo com Johnson e Duberley (2000), apesar de a busca por verdades absolutas, por intermédio da objetividade, remontar a épocas anteriores a Platão, a corrente epistemológica intitulada positivismo surgiu em um período pósiluminista. Certamente, a figura mais referenciada nesse contexto é Auguste Comte, especialmente por ter cunhado tanto o termo positivismo, quanto a denominação sociologia. O pensamento positivo marca a sobreposição do concreto e observável ao imaginado e interpretável (OLIVEIRA; COSTA; KOVACS, 2011).

Este artigo tem por objetivo sistematizar uma forma de es- 
tudo da epistemologia positivista, de modo a propiciar um melhor aproveitamento didático-pedagógico de estudantes, especialmente em nível de pós-graduação Stricto Sensu. Para o alcance do objetivo, propôs-se a: (i) apresentar uma proposta didático-pedagógica para o estudo do positivismo na área de Administração; (ii) apresentar os resultados da prática desta proposta, na forma de oficina, em uma turma de doutorado em administração; e (iii) apresentar elementos resultantes da experiência em sala de aula que permitam a ligação do positivismo com outras epistemologias.

As utilizações de experiências didáticas fornecem um dinamismo para o ambiente de sala de aula, sendo comum haver relatos em estudos que abordam o Ensino e a Pesquisa, como a obra de Davel, Vergara e Ghadiri (2007), que apresenta diferentes formas de ensino e aprendizagem em Administração com o uso de diversas manifestações de Arte (poesias, fotografias, filmes, etc.) Destaca-se, também, o modelo adotado pelas obras de Machado e Matos (2012) e de Costa e Ramos (2015), que apresentam experiência de utilização de filmes para ampliar a reflexão e o amadurecimento de ideias com estudantes de Administração.

$\mathrm{O}$ artigo está estruturado em mais quatro seções, de modo que, na primeira, foi fornecida uma contextualização da epistemologia no tempo e no espaço. Na seguinte, abordaram-se aspectos teóricos inerentes à epistemologia positivista. Em seguida, nas seções 3.1. e 3.2., para facilitar a interação entre professores e alunos em sala de aula, buscou-se explorar as principais contribuições da filosofia de Comte, no Brasil, no século XIX. Este período foi selecionado para ser analisado, pois, devido às várias transformações sociais, econômicas e políticas pelas quais o país passou na época, é possível fazer um diálogo do positivismo em conjunto com a ótica do binômio ruptura-continuidade presentes nos pensamentos de Gaston Bachelard e de Thomas Kuhn. Após isso, foi apontada uma breve lembrança da contribuição da epistemologia de Comte no século XX. Em seguida, colocou-se em evidência a questão do positivismo na atualidade. Especificamente, no tópico 3.3, apresentou-se como o Positivismo vem sendo empregado em pesquisas na ciência da Administração.

No item 4, discutiram-se os procedimentos metodológicos adotados e na seção 5, apresentou-se uma experiência de proposta didático-pedagógica com fins de auxiliar docentes e discentes na condução de aulas voltadas a essa temática. Por fim, no tópico 6, são apresentadas as considerações finais da proposta.

\section{CONTEXTUALIZAÇÃO}

O positivismo busca, sob a forma de seu método de investigação, revelar, assim como nas ciências naturais (a física, a química e a biologia, por exemplo) leis gerais que regulam as relações sociais (COSTA, 2005). Esse desejo de apropriar-se dos métodos empregados nas ciências físicas e naturais, com intuito de empregá-los nas ciências sociais, direcionou filósofos à compreensão da realidade social fundada em verdades monolíticas e indissolúveis. Destaca-se uma interessante sutileza deste processo quando Comte, ainda em fase incipiente de seu trabalho, chama a atual sociologia de "física social" (GIANNOTTI, 2007). As inquietações que levam um filósofo a buscar o conhecimento, possivelmente, fomentaram a concepção da abordagem positivista.

Apesar das limitações dessa abordagem epistemológica, cabe destacar o mérito de seu esforço inicial em sistematizar as análises científicas da sociedade. É interessante mencionar que, embora a abordagem seja duramente criticada, é amplamente empregada em pesquisas de administração, apesar de o termo em si não ser frequentemente adotado e, segundo Johnson e Duberley (2000), quando usado, a conotação é crítica, ou ainda, de distanciamento.

\section{ASPECTOS TEÓRICOS}

Como forma de fornecer subsídios teóricos aos leitores e participantes do experimento, buscou-se explorar nessa seção as principais 
contribuições da filosofia positivista desde o século XIX. Vale, no entanto, ressaltar que não se trata de uma "defesa" da epistemologia positivista, mas de uma contextualização histórica, essencial ao processo de ensino-aprendizagem. Para tanto, foram discutidos os seguintes pontos: o surgimento do positivismo; o legado da epistemologia de Comte, fazendo uma análise dessa herança com base no binômio ruptura-continuidade, de Bachelard e de Kuhn e; por fim, abordou-se a forma como o positivismo se relaciona com os estudos de administração.

\subsection{EASSIM NASCEU O POSITIVISMO [...]}

O fundador de uma das mais influentes epistemologias dos últimos séculos foi Auguste Comte, um filósofo francês, nascido em 1798. Em 1814, Comte ingressou na École Polytecnique, em Paris. Na passagem por aquela escola, sua convivência com Saint-Simon (17601825), que tanto o entusiasmou, e com outros intelectuais importantes como Turjot e Adam Smith, influenciaram seu modo de pensar. Seus trabalhos tiveram grande repercussão no Brasil. Entre eles, destacam-se: o curso de filosofia Positiva, publicado entre 1830 e 1842, e o Sistema de Política Positiva, no qual ele expôs as normas da chamada "Religião da Humanidade". Em sua primeira obra, Comte relatou que a humanidade passaria por "Três Estágios": o teológico, em que haveria predomínio das forças sobrenaturais; o metafísico, caracterizado pela crítica vazia, sem nexo e pela desordem espiritual, fruto do liberalismo; e o positivo, que superaria as explicações insuficientes do mundo, mediante a introdução das leis científicas no lugar das hipóteses religiosas ou metafísicas (GIANNOTTI, 2007).

O Positivismo, como epistemologia, influenciou as ciências sociais por mais de um século. Desde 1830, quando foi empregado pela primeira vez por Saint-Simon, o termo abriu caminho para um estudo mais reflexivo sobre a ciência, sua organização, sua formação, seu funcionamento e produção intelectual (JAPIASSU, 1992). A gênese do Positivismo ocorreu no século XIX, em um momento de transformações sociais, econômicas, políticas, ideológicas, tecnológicas e científicas profundas decorrentes da consolidação do capitalismo, como modo de produção, por meio da propagação das atividades industriais na Europa e em outras regiões do mundo. O "século de Comte" e da França foi marcado pela busca constante de uma "Deusa" chamada razão. Comte depositou sua fé em uma "Nova Religião", caracterizada pela junção entre a ciência e a tecnologia, tidas como a panaceia da humanidade, no contexto da expansão do capitalismo industrial (VALENTIM, 2010).

$\mathrm{Na}$ doutrina de Comte, o indivíduo é analisado como integrante de um organismo coletivo e se subordina à família, à Pátria e à humanidade. O grande lema positivista é: o amor por princípio e a ordem por base; o progresso por fim (COMTE, 1978) ([1798-1857]). A filosofia de Comte não aceita que a explicação dos fenômenos naturais, assim como dos sociais, provenha de um só princípio. Nela, a visão dos fatos abandona a consideração das causas dos fenômenos (Deus ou natureza) e pesquisa suas leis.

No Brasil, o positivismo foi dividido em duas correntes distintas: a ortodoxa, seguidora da Religião da Humanidade, representada pelos apóstolos Miguel Lemos (1854-1917) e Teixeira Mendes (1855-1927), que, em 1881, fundaram a Igreja Positivista Brasileira; e a dissidente ou heterodoxa, cujos nomes mais importantes foram Luis Pereira Barreto, Alberto Salles, Pedro Lessa e o Tenente Coronel Benjamin Constant. $\mathrm{O}$ crescimento do interesse por esta filosofia acabou provocando um fenômeno, que ganhou mais repercussão no Brasil que na própria França (LINS, 1964).

Durante muitos anos, admitiu-se que o positivismo tivesse penetrado no Brasil pelo ensino das ciências exatas, por meio da Escola Militar e da Marinha de Guerra ou das lições de química e física da Escola Politécnica. Embora a influência maior tenha-se dado por essa via, sabe-se que, em 1844, Justiniano da Silva Gomes defendeu sua tese na área de biologia, aludindo explicitamente a Auguste Comte, à 
Lei dos Três Estados e ao Método Positivo. Por essa razão, Lins (1964) considera Justiniano o primeiro positivista brasileiro.

Lins (1964) comenta, ainda, que o passo mais importante, contudo, fora dado por Luís Pereira Barreto (1840 - 1923), com a obra "As Três Filosofias", na qual a positivista era apontada como capaz de substituir a tutela intelectual exercida pela Igreja Católica. Aponta, também, que a grande adesão, senão a principal delas, foi a de Benjamin Constant Botelho de Magalhães (1836 - 1891), consagrado mestre da Escola Militar, devido à sua grande competência didática (LINS, 1964).

Benjamin Constant nasceu em Niterói. Foi militar, engenheiro, professor e estadista. Adepto do positivismo, em sua vertente filosófica e religiosa - cujas ideias se difundiram entre a jovem oficialidade do Exército. Participou da Guerra do Paraguai, construiu pontes, trincheiras e fez mapas. Pegou malária nesta Guerra e, ao voltar ao Brasil, a doença foi gradativamente o debilitando, o que acabou provocando sua morte, aos 55 anos, em 1891 (LINS, 1964).

Apesar desse sacrifício à carreira militar, a vocação de Benjamin Constant não era essa. Inspirado pelo pai, Constant sempre quis ser professor. E foi nesta carreira que Benjamin mais contribuiu com a penetração das ideias positivistas no Brasil. É relevante ressaltar que sua ação profissional se deu em torno das primeiras instituições brasileiras, em que ensinou matemática de nível superior. Mas foi nas Escolas Militares que ele se tornou o grande divulgador da filosofia positivista, e um líder entre os militares, o que acabou resultando em grandes transformações políticas e educacionais no Brasil (LINS, 1964).

\subsection{POSITIVISMO NO BRASIL: O LEGA- DO POSITIVISTA NO FINAL DO SÉ- CULO XIX E UMA ANÁLISE DESSA HERANÇA COM BASE NO BINÔ- MIO RUPTURA-CONTINUIDADE DE BACHELARD E DE KUHN}

Trata-se de uma tarefa extremamente ousada analisar a herança positivista sob a ótica de outros filósofos. Mais ousado ainda é inserir alguns pontos de vista dos estudos de Gaston Bachelard e de Thomas Kuhn sob uma perspectiva comparada. O quadro se torna mais complexo, quando se faz isso nos limites de um artigo. Por esta razão, escolheu-se um único enfoque, uma única linha de abordagem, que privilegie alguns conceitos e, assim, se estabeleça um paralelo entre as epistemologias de três grandes filósofos: Comte, Bachelard e Kuhn. Compreende-se que esta prática poderá contribuir para que professores e alunos possam interligar o positivismo com outras epistemologias, evidenciando algumas semelhanças e diferenças existentes entre elas.

Para facilitar o entendimento, optou-se por fazer a análise com base nos acontecimentos transcorridos no final do século XIX, quando as influências positivistas foram sentidas em todos os campos do poder nacional (econômico, social, político e militar) e contribuíram com a queda do Império e com a Proclamação da República.

Um aspecto que contribuiu para o fim do Império foi a questão militar. A posição secundária dada aos militares pelo Imperador D. Pedro II, por si só, já era uma quebra de paradigma, já que os militares tinham uma posição de destaque no Primeiro Reinado, ocasião em que os engenheiros militares construíram fortalezas com elevado grau de conhecimento científico e tecnológico. No Segundo Reinado, esse conhecimento se perdeu. Além disso, após a Guerra do Paraguai, o Brasil, vitorioso, colocou-se em posição de destaque no cenário mundial. Na visão dos militares, que começavam a sofrer influências positivistas, difundidas por Benjamin Constant, caberia alforriar os soldados negros que lá combateram: "a missão do Exército era 
muito mais nobre do que caçar escravos fujões." (AZEVEDO, 2011, p. 10). A partir de então, alguns militares encontraram na filosofia Comtiana e nas questões que inquietavam o país (desordem social, crise abolicionista e religiosa, etc.), o suporte para rejeitar a cultura imperial, que se baseava nos estudos jurídicos e não nas ciências sociais e naturais. Utilizou-se, assim, o positivismo como um instrumento ideal para a formulação das exigências de uma nova forma de autoridade para o Brasil.

Naquela oportunidade, as elites brasileiras perceberam que havia necessidade de ruptura com a ordem vigente. A monarquia estava enfraquecida, o paradigma vigente não estava atendendo mais às demandas sociais e, desse modo, era necessária a mudança de regime ou uma ruptura provocada por todas as camadas da sociedade. A união da questão militar, com as mazelas sociais, com a perda de poder da igreja e de parte da aristocracia serviram de munição explosiva para o estopim aceso no seio do corpo do Exército. Era justamente o que precisavam os jovens oficiais do Exército, para nortear suas decisões, em um regime imperial em decadência. Dessa forma, Benjamin Constant pode ser visto como um homem que soube unir os ideais positivistas com as aspirações da juventude militar. Ele chegou a ser percebido, por exemplo, como "pacificador do que revolucionário; não destruiu, nem subverteu. Pelo contrário, poupou a Pátria da perturbação, desordem e morte. Em meio às espadas desnudas, era o símbolo da concórdia: persuadia, abrandava e dirigia." (LINS, 1964, p. 314).

É possível conjecturar que, na visão de Benjamin Constant e da epistemologia de Comte, a ruptura provocada pela nova forma de governo não poderia significar uma continuidade das mazelas sociais vigentes no Império. Seria necessária uma conversão da população, que deveria caminhar de forma harmônica, ordenada e científica para o suposto Progresso. Sob a ótica de Kuhn, o advento da República também significaria uma ruptura com o passado. Houve diálogo na sociedade, tensões foram geradas. Havia defensores para diversos paradigmas (monarquia, república, manutenção do Império, etc.). Para Kuhn, o que houve foi uma quebra de paradigma. Por outro lado, ao observar a população (o sujeito), existiu um continuísmo da ordem social, já que não se modificou a condição de vida das massas. Segundo Azevedo (2011), seria muito difícil que uma população semianalfabeta se convertesse e, a partir daquele momento, assumisse uma condição que favorecesse o desenvolvimento científico. Este fato corrobora o pensamento de Kuhn, uma vez que um novo paradigma conserva boa parte das realizações científicas passadas, e que o novo conhecimento sempre resgata parte do anterior, sob nova ótica.

A ideia de continuidade parece ainda mais clara em Bachelard, uma vez que, no conceito de perfil epistemológico, está garantida a permanência das diversas doutrinas filosóficas. Desse modo, a vertente epistemológica de Bachelard criticaria o positivismo que não conseguiu converter a visão da população que continuou com o pensamento subalterno e não se emancipou, como se ainda tivesse um senhor a obedecer. A Proclamação da República foi um evento que caracterizou muito bem o descontinuísmo histórico de Bachelard, no qual um momento histórico na ciência não é imediatamente seguido por outro sem que haja cortes ou rupturas.

No século XX, o positivismo foi gradativamente perdendo o ímpeto, mas deixou suas marcas. Pertencem ao saldo positivo: o pensamento antropológico antirracista; a exigência sempre reiterada da austeridade financeira no trato da coisa pública; o interesse pela humanização das condições de trabalho operário, que resultou em propostas de leis trabalhistas, implementadas quando políticos gaúchos de formação positivista ascenderam ao poder central em 1930 (LINS, 1964).

\subsection{A ADMINISTRAÇÃO E O POSITI- VISMO}

Vale ressaltar que, embora a abordagem positivista seja duramente criticada, é amplamente empregada em pesquisas de administração. Contudo, o termo "positivismo" não é em- 
pregado com frequência quando a abordagem é adotada. Alguns questionamentos podem ajudar no processo de condução do encontro pedagógico, levando os participantes a refletirem. Os autores sugerem as seguintes reflexões: por que pesquisadores evitam o uso do termo ao usarem a abordagem? Será que eles se envergonham em assumir o uso da abordagem epistemológica positivista? Haveria um recente preconceito da academia em relação a esse paradigma? $\mathrm{O}$ uso da abordagem seria suficiente para rotular um pesquisador como um "sujeito positivista"?

No processo de construção do conhecimento em administração, é comum que autores desenvolvam argumentos equivocados sobre o positivismo, por vezes tratando-o como uma abordagem metodológica (AZEVEDO et al., 2011). O que esses autores não levam em consideração é que uma pesquisa de abordagem metodológica qualitativa, como a análise de conteúdo, pode empregar, sem reserva, a abordagem epistemológica positivista (DELLAGNELO; SILVA, 2005). Mesmo abordagens metodológicas qualitativas, que não empregaram como paradigma epistemológico o positivismo, costumam sofrer fortes influências da corrente. Chizzotti (2003, p. 228) reforça a argumentação alegando que "[...] a pesquisa qualitativa, ainda atada ao positivismo, empenha-se em dar uma fundamentação rigorosa e formalizar os métodos científicos qualitativos, recorrendo a algum expediente quantitativo." Desse modo, frequentemente, é possível se deparar com pesquisas que aparentam seguir um protocolo ou uma regra geral: criticam o positivismo; apresentam alguma abordagem metodológica qualitativa e, ao final, "se desculpam" pela impossibilidade de seus resultados não poderem ser generalizados. Ver Mattos (2006).

Mesmo sob tantas críticas, problemas e lacunas, o paradigma positivista continua sendo amplamente utilizado. Por essa razão, permanecem as seguintes dúvidas: por que continua sendo usado? E já que está sendo empregado, por que é tão criticado? Será que tais críticas não passam de um mero modismo? No Brasil e no mundo, é possível elencar diversos traba- lhos que destacam a orientação positivista de pesquisadores em administração (DALMORO et al., 2007; VERGARA; CARVALHO, 2002; BUELENS et al., 2008; GRIMMER; HANSON, 2007; RODRIGUES; CARRIERI, 2001; MACHADO; MATOS; PINHEIRO, 2013) além de outros. É compreensível o desejo de pesquisadores pregarem e defenderem crenças acadêmicas, todavia o discurso dominante, em termos gerais, parece se distanciar da prática a cada novo trabalho publicado.

\section{PROCEDIMENTOS METODOLÓ- GICOS}

Tendo em vista as características deste trabalho, o estudo empírico realizado foi desenvolvido a partir de uma abordagem qualitativa, dado que o interesse fundamental foi relatar uma experiência pedagógica, na forma de uma oficina e, a partir daí, desenvolver a proposição. Os diversos relatos de processos de ensino e aprendizagem em Administração da obra de Davel, Vergara e Ghadiri (2007) serviram de referência para a elaboração deste estudo. Reforça-se, também, a utilização de filmes para ampliar a reflexão e o amadurecimento de ideias com os estudantes de curso de Administração conforme apresentado nas obras de Machado e Matos (2012) e de Costa e Ramos (2015), em especial na parte apresentação de um capítulo de uma série televisiva. Porém, o presente trabalho é bastante análogo da descrição apresentada por Monteiro, Munhoz e Bertholini (2012) quando realizaram um encontro pedagógico com um grupo de doutorandos do curso de Administração para apresentar e vivenciar, de forma prática, os aspectos relacionados à epistemologia Histórica e das ideias propostas por Gaston Bachelard.

O trabalho supre uma lacuna encontrada em estudos da área de educação e ensino de Administração. São poucos os relatos encontrados na literatura que tratam de uma estrutura sistematizada de ensino na área. É possível encontrar estudos de mesma natureza na área de educação, educação física e ensino de ciências (Ex: 
Biologia, Física, Química, etc.). Desse modo, este estudo procurou sistematizar uma forma de estudo da epistemologia positivista, a partir de um encontro pedagógico de epistemologia em Administração, propiciando um melhor aproveitamento didático-pedagógico dos estudantes. Acredita-se que esse relato possibilite sua replicação por outros estudiosos e educadores. Neste ponto, também, apresentam similaridades com a proposta de Monteiro, Munhoz e Bertholini (2012).

Os tipos de investigação utilizados foram a pesquisa bibliográfica e a documental para um melhor embasamento do conteúdo exposto durante o encontro pedagógico. Foram objetos de consulta e análise as seguintes fontes de dados: livros, artigos, músicas e obras audiovisuais.

A realização de um encontro pedagógico, na forma de oficina, serviu como o caso a ser estudado, pois, neste ambiente, os pesquisadores puderam interagir com os alunos de uma turma de Doutorado em Administração. Esta experiência foi realizada no mês de abril de 2011 durante uma aula da disciplina de "Epistemologia" que foi realizada em uma instituição de ensino no estado do Rio de Janeiro.

$\mathrm{Na}$ seção seguinte, será relatado, detalhadamente, cada um dos passos realizados na oficina desde a etapa de planejamento até a conclusão da experiência, com a análise dos resultados obtidos.

\section{PROPOSTA DE DESENVOLVIMEN- TO DA OFICINA}

Nesta seção, buscou-se fornecer recursos didáticos para a condução de encontros pedagógicos, oficinas, e/ou aulas, no intuito de apresentar a epistemologia positiva. O material escolhido pode ser utilizado tanto em atividades de nível graduação, como de pós-graduação stricto sensu. Para melhor ilustrar a proposta, apresentam-se a seguir as etapas que compuseram a oficina.

\subsection{O PLANEJAMENTO DO ENCONTRO}

$\mathrm{O}$ encontro pedagógico foi desenhado e planejado para uma turma de doutorandos em administração. Portanto, foi necessário elaborar um detalhado e consistente planejamento de aula, embora fosse interessante dar liberdade para a criatividade aflorar no processo. Inicialmente, como fontes de inspiração e exemplo, foram consultadas fontes que visavam à utilização da arte em administração, principalmente, no contexto de ensino e aprendizagem (CARVALHO; DAVEL, 2005; DAVEL; VERGARA; GHADIRI, 2007). Buscou-se tratar o positivismo e suas influências utilizando recursos de mídia. Para tanto, realizou-se uma pesquisa preliminar em busca de poesias, letras de músicas, quadrinhos, documentários, seriados e filmes que retratassem a epistemologia em questão.

Após a busca, selecionou-se uma música como recurso à oficina, e as cópias da letra da música foram impressas para cada aluno. Escolheu-se, também, um capítulo de seriado de televisão como forma de analisar o emprego do paradigma positivista. Com os recursos em mente, iniciou-se a elaboração de um plano de aula para servir de orientação à futura viabilização do encontro. O resumo do plano de aula pode ser visualizado no Quadro 1, o qual está dividido conforme os seguintes elementos: os assuntos escolhidos, as estratégias abordadas e os recursos utilizados para a melhor compreensão dos alunos em sala de aula. 


\begin{tabular}{|c|c|c|}
\hline $\begin{array}{c}\text { Conteúdos } \\
\text { (itens trabalhados durante a aula) }\end{array}$ & $\begin{array}{c}\text { Estratégia } \\
\text { (procedimentos de ensino) }\end{array}$ & $\begin{array}{c}\text { Recursos } \\
\text { (Materiais de apoio) }\end{array}$ \\
\hline $\begin{array}{l}\text { Visão inicial do Positivismo; } \\
\text { Conceitos básicos; } \\
\text { Pensamento de uma época no } \\
\text { Brasil; } \\
\text { Contexto nacional. }\end{array}$ & $\begin{array}{l}\text { Abertura; } \\
\text { Execução da música "Positivismo" do } \\
\text { Noel Rosa e Orestes Barbosa; } \\
\text { Interpretação da letra; } \\
\text { Discussão em dupla; } \\
\text { Levantamento de uma questão. }\end{array}$ & $\begin{array}{l}\text { Letra da música impressa } \\
\text { para cada dupla; } \\
\text { Aparelho de áudio; } \\
\text { Duração sugerida da } \\
\text { atividade de } 30 \text { minutos. }\end{array}$ \\
\hline $\begin{array}{l}\text { O Positivismo no cotidiano; } \\
\text { Método científico; } \\
\text { A influência em algumas } \\
\text { profissões; }\end{array}$ & $\begin{array}{l}\text { Execução de um episódio do } \\
\text { seriado "House" editado (KELLEY; } \\
\text { CLARCKSON, 2011); } \\
1^{\circ} \text { Momento - Interpretação do vídeo; } \\
\text { Discussão em dupla; } \\
\text { Levantamento de uma questão; } \\
2^{\circ} \text { Momento - Discussão em quarteto; } \\
\text { Levantamento de questão (tentativa de } \\
\text { consenso) }\end{array}$ & $\begin{array}{l}\text { Aparelho de projeção } \\
\text { audiovisual; } \\
\text { Duração sugerida: } \\
\text { vídeo de } 20 \text { a } 40 \text { minutos; } \\
1^{\circ} \text { momento de } 25 \text { minutos; } \\
2^{\circ} \text { momento de } 25 \text { minutos }\end{array}$ \\
\hline $\begin{array}{l}\text { Contraponto de visões; } \\
\text { Opiniões dos grupos; } \\
\text { Nivelamento conceitual. } \\
\end{array}$ & $\begin{array}{l}\text { Apresentação das questões elaboradas } \\
\text { pelos grupos; } \\
\text { Explicação das interpretações; }\end{array}$ & $\begin{array}{l}\text { Projeção das questões; } \\
\text { Duração sugerida de } 50 \\
\text { minutos. }\end{array}$ \\
\hline $\begin{array}{l}\text { Ligação do Positivismo com a } \\
\text { área de Administração e com } \\
\text { outras epistemologias; } \\
\text { Apresentação de fraquezas, } \\
\text { forças e peculiaridades do } \\
\text { Positivismo; }\end{array}$ & $\begin{array}{l}\text { Debate geral utilizando-se as questões } \\
\text { formuladas anteriormente; } \\
\text { Encerramento. }\end{array}$ & $\begin{array}{l}\text { Duração sugerida de } 50 \\
\text { minutos. }\end{array}$ \\
\hline
\end{tabular}

Quadro 1 - Resumo do Plano de Aula

Fonte: elaborado pelos autores.

Durante o planejamento do encontro pedagógico, estabeleceu-se o tempo necessário para a realização de cada atividade proposta. Para tanto, foi necessário editar o capítulo do seriado (filme em DVD) (KELLEY; CLARCKSON, 2011), a fim de retirar alguns trechos que prolongariam a exibição e não seriam necessários à compreensão do que seria proposto em relação ao positivismo. A edição foi feita com o devido cuidado para não dificultar a compreensão da história apresentada.

\subsection{A EXECUÇÃO DO PLANO NO ENCONTRO PEDAGÓGICO}

Inicialmente, com auxílio de um projetor, apresentaram-se aos alunos as atividades previstas e o planejamento do tempo de duração de cada atividade. Também vale ressaltar que os alunos foram instruídos a realizar leitura prévia sobre o tema em fontes indicadas (VERGARA, 1990; JOHNSON; DUBERLEY, 2000). Foi enfatizado que todas as atividades deveriam seguir rigorosamente o cronograma proposto, como forma de atender aos princípios de "ordem" e "progresso" realçados pelo positivismo.

Dando continuidade, apresentamos a letra da música "Positivismo", escrita por Noel Rosa e Orestes Barbosa no ano de 1933, a qual pode ser lida no Quadro2: 
A verdade, meu amor, mora num poço

É Pilatos lá na Bíblia quem nos diz

E também faleceu por seu pescoço

$\mathrm{O}$ autor da guilhotina de Paris (2x)

Vai, orgulhosa, querida

Mas aceita esta lição:

No câmbio incerto da vida

A libra sempre é o coração

$\mathrm{O}$ amor vem por princípio, a ordem por base

O progresso é que deve vir por fim
Desprezastes esta lei de Augusto Comte

E fostes ser feliz longe de mim (duas vezes)

Vai, coração que não vibra

Com teu juro exorbitante

Transformar mais outra libra

Em dívida flutuante

A intriga nasce num café pequeno

Que se toma pra ver quem vai pagar

Para não sentir mais o teu veneno

Foi que eu já resolvi me envenenar

Quadro 2 - Letra da Música Positivismo

Fonte: (SANTOS; SILVA, 2010).

Em seguida, a letra da música foi distribuída para cada aluno. Enquanto a música tocava, os alunos puderam acompanhar atentamente cada um dos versos e estrofes, que estavam sendo projetadas na tela.

Em seguida, foi proposto que os alunos formassem duplas para discutir a letra da música segundo os conhecimentos adquiridos nas leituras prévias sobre o positivismo. Sugerimos a eles que elaborassem, em conjunto, uma pergunta para um debate proposto para a parte final do encontro pedagógico.

$\mathrm{Na}$ segunda parte do encontro, exibiu-se o capítulo do seriado americano House, episódio 14 da $7^{\mathrm{a}}$ temporada (KELLEY; CLARCKSON, 2011). Este foi escolhido, em especial, devido ao fato de apresentar elementos positivistas no ambiente da medicina. No filme, ao buscar identificar os mecanismos para cura de um paciente, a equipe médica estabelece diagnósticos a partir dos sintomas relatados pelo mesmo ou por exames clínicos realizados. Assim, buscam identificar a doença que origina todos os sintomas, na medida em que vai tratando o paciente, para evitar que ele sinta dores ou incômodos decorrentes da patologia não diagnosticada precisamente.

Após a exibição do capítulo do seriado editado, solicitou-se aos alunos que, ainda em duplas, discutissem sobre as influências do positivismo no vídeo, ao mesmo tempo em que se questionava se eles gostariam de reescrever a questão formulada na etapa anterior. Em segui- da, solicitou-se que os discentes formassem um quarteto, a partir da junção de duas duplas, em uma tentativa de que pudessem discutir sobre uma posição distinta ou semelhante àquela já tratada nas duplas iniciais. Essa medida acabou tornando-se uma espécie de triangulação entre os estudantes, para uma tentativa de consenso na formulação de uma pergunta única pelo quarteto formado (ABDALLA et al., 2018).

Realizou-se um breve intervalo e, durante ele, as questões formuladas pelos quartetos foram recolhidas e inseridas nos slides para estimular o debate posterior. Era esperado que fossem sete perguntas devido à quantidade de quartetos formados (sete). Todavia, no total, os alunos suscitaram o debate com quatorze perguntas que podem ser observadas no Quadro 3.

No retorno do intervalo, foi proposto que os alunos se sentassem formando um círculo na sala de aula, preferencialmente próximos aos integrantes dos quartetos formados. Apresentou-se, no projetor, cada uma das perguntas elaboradas e solicitou-se que um representante do quarteto explicasse o que levou à formulação daquele questionamento. Todos apresentaram os questionamentos formulados e escutaram o que foi proposto pelos demais colegas.

A partir dos questionamentos levantados, iniciou-se um debate geral com toda a turma sobre o positivismo, suas influências, semelhanças e diferenças com outras epistemologias e como essas questões foram apresentadas por meio dos recursos didáticos utilizados pela equipe que elaborou o encontro. 


\section{Quarteto 1}

- Até que ponto o positivismo é típico/inerente ao estudo de organizações empresariais modernas?

- Existe um vínculo entre epistemologia e o tipo de organização pesquisada?

\section{Quarteto 2}

- É possível haver uma abordagem única, de forma que se use somente o positivismo (ou a racionalidade analítico-empírica) para resolver problemas?

- Existe papel para a intuição no processo de descoberta ou ela se dá unicamente pelas evidências empíricas?

\section{Quarteto 3}

- O que é a verdade na ótica positivista? Não seria uma verdade muito generalizada para que possa funcionar em uma ciência social?

- O amor pelo princípio, a ordem por base, e o progresso por fim são os únicos caminhos para a felicidade? Noel Rosa acha que essa é uma questão relativa porque seu objetivo de amor foi feliz por outra via, contrariando o princípio da verdade absoluta e generalizada.

\section{Quarteto 4}

- É possível a Administração prescindir do positivismo?

- E é desejável a Administração prescindir do positivismo?

- A redução de discussões complexas a testes de hipóteses pode desvincular a teoria da prática criando uma falsa (?) dicotomia entre estas duas dimensões/aspectos?

- O criador da guilhotina morreu decapitado... Neste caso, a relação sujeito/objeto resolveu-se de forma contundente?

\section{Quarteto 5}

- Considerando que a racionalidade analítico-empírica é orientadora das ciências sociais orientadas pelo positivismo, como se pressupõe trabalhos cujo teor metodológico necessariamente se sustenta em técnicas que consideram o sujeito como um sujeito cognoscente?

- O deslocamento da realidade social leva ao distanciamento da ciência para com o sujeito; propõe-se a existência de uma verdade única; onde o sujeito está situado no desenvolvimento teórico, por exemplo?

\section{Quarteto 6}

- Até que ponto é possível a separação entre o sujeito e o objeto de pesquisa? Ainda que possível, esta separação é ou não benéfica? Em que situações?

\section{Quarteto 7}

- Um conceito que permeia a Teoria das Organizações é o conceito de organizações reificadas. Considerando que a organização reificada escapa do indivíduo e se estabelecem num plano além do humano, ela não se tornaria um objeto sujeito a algum tipo de lei natural?

Quadro 3 - Perguntas formuladas pelos quartetos para o debate geral

Fonte: elaborado pelos autores com base na oficina realizada.

\subsection{O DEBATE EM QUESTÃO}

As questões formuladas foram essenciais para a realização de um debate que permitiu uma boa finalização do encontro. Em algumas questões, os alunos chegaram a utilizar pequenos trechos da música de Noel Rosa e Orestes Barbosa. Tal fato demonstra que a utilização de elementos de arte contribui bastante para se alcançar os objetivos propostos. Os alunos utilizaram elementos de análise da música que corroboraram a breve explicação proposta por Tota (2001), na qual o autor ressalta as ideias do progresso bem como dos possíveis problemas 
aprofundados na época como os juros exorbitantes e a dívida postergada pelo governo.

Em relação ao filme, pode-se afirmar que, mesmo com a decisão de se apresentar um episódio que retrata um cenário do cotidiano de um hospital, os alunos elaboraram perguntas que demonstram a relação do positivismo com a Administração ou com os estudos das organizações, indo ao encontro do que foi proposto por Carvalho e Davel (2005) e Davel, Vergara e Ghadiri (2007).

Outras questões buscaram identificar elementos característicos do positivismo como a existência de uma única verdade, a relação entre sujeito/objeto e a possibilidade de generalização. $\mathrm{O}$ debate se prolongou até o final do horário estabelecido para a conclusão do encontro. Vale ressaltar que todas as atividades foram realizadas conforme estabelecido no cronograma. O recurso da verificação do tempo por meio de um cronômetro e da organização das atividades por etapas foram realçados pelos elaboradores do encontro como forma de demonstrar, na prática, a utilização de alguns elementos objetivos do positivismo.

Desse modo, acredita-se que o objetivo da realização do encontro/oficina foi alcançado. De uma forma lúdica, leve e criativa, foram utilizados recursos que permitiram explorar os conhecimentos prévios dos alunos sobre o assunto, bem como aqueles abordados somente no próprio evento.

\section{CONSIDERAÇÕES FINAIS}

A discussão da corrente epistemológica positivista tem grande importância na ciência da Administração. Seu estudo e reflexão têm reconhecido espaço em pesquisas de diversos campos da Administração: Organizações, Estratégia, Marketing, Recursos Humanos, Finanças, Produção, Logística, Sistemas de Informação, Administração Pública, Ensino \& Pesquisa, Inovação, além de outros.

Procurou-se, neste relato, sistematizar uma forma de estudo da epistemologia positivista, propiciando um melhor aproveitamento didático-pedagógico dos estudantes. Para isso, foi apresentado um debate acerca dos principais conceitos da epistemologia positivista, de forma a fornecer insumos didático-pedagógicos àqueles que desejam explorar encontros sobre esta temática nos níveis de graduação ou pós-graduação, especialmente em nível stricto sensu. Para a realização do objetivo proposto, foram apresentadas, também, proposições teóricas que embasaram este artigo e o encontro pedagógico, assim como as ferramentas didáticas, execução do encontro e os resultados gerados pelos participantes condutores do encontro.

Tendo como pressuposto o fato de que um encontro pedagógico de qualidade sobre esta epistemologia exige uma profunda reflexão teórica e conceitual, buscou-se apresentar conceitos-chave sobre a epistemologia positivista como a história do seu maior pensador e fundador, Auguste Comte; a história da ascensão positivista na Europa e outras regiões; a história do positivismo no âmbito Brasil e seus principais pensadores como Miguel Lemos, Teixeira Mendes, Pereira Barreto e Benjamin Constant; uma análise da herança positivista brasileira com base no binômio ruptura-continuidade de Bachelard e de Kuhn; o uso desta abordagem em pesquisas contemporâneas de Administração assim como suas principais críticas; e, por fim, foram apresentadas as principais influências.

Apresentou-se, também, a dinâmica do encontro, desde a sua preparação até os resultados obtidos. Primeiramente, elaborou-se a estratégia pedagógica. Para isso, realizou-se um planejamento, buscando detalhar os assuntos abordados, as estratégias de execução e os recursos necessários para a realização do encontro. A seguir, foram apresentados e detalhados os procedimentos da execução deste plano, entre os quais se pode citar a projeção da letra da música "Positivismo", do vídeo do seriado House, a solicitação de elaboração de perguntas pelos participantes e o debate geral. Por fim, foram apresentados os resultados obtidos com o encontro, seus questionamentos, os principais pontos abordados e a metodologia utilizada. 
Com a apresentação das informações conceituais sobre a epistemologia positivista e as impressões sobre a estratégia didático-pedagógica adotada no encontro, conclui-se que os objetivos propostos foram atingidos, tratando o ensino de epistemologia, e, especificamente, do paradigma positivista de forma lúdica, interativa, criativa, profunda e participativa, distanciando-se das tradicionais aulas expositivas.

Recomenda-se que a experiência em sala de aula seja replicada em outras turmas do ensino superior, bem como a realização de experiência semelhante com outras epistemologias. Um encontro pedagógico de epistemologias distintas ou complementares também pode ser realizado com outra perspectiva na relação de ensino-aprendizagem do conteúdo proposto. Vale ressaltar que a experiência desenvolvida na oficia proposta possui algumas limitações: (i) A experiência foi realizada com um grupo de discente de nível Strictu Sensu (Doutorado). Ou seja, para a implementação em outros níveis, recomendam-se as devidas modificações e adaptações; (ii) $\mathrm{O}$ experimento foi conduzido na área de Administração. Dessa forma, em outros contextos das Ciências Sociais Aplicadas, devem ser estudadas possíveis alternativas pedagógicas; (iii) Concorda-se que a estrutura pedagógica pode ser transportada para outras vertentes epistemológicas. Contudo, considera-se que, para cada epistemologia, possivelmente existam estruturas pedagógicas mais adequadas, semelhante ao estudo de Monteiro, Munhoz e Bertholini (2012) com a epistemologia histórica.

\section{REFLECTING ABOUT OBJECTIVITY: A TEACHING EXPERIENCE ON THE POSITIVISM OF COMTE}

\begin{abstract}
The Positivism emerged as one of the first streams of thought systematically recognized as a social science epistemology. It attempted to systematize a way to study the positivist episte-
\end{abstract}

mology, providing better educational-learning student achievement. The empirical study was carried out from a qualitative approach, reporting a learning experience, in the form of workshop. This served as a case study because in this environment it is possible to interact with the doctoral students of Business Administration course. By means of this this report, the main concepts of positivist epistemology are debated and provide didactic and pedagogical inputs to those wishing to explore meetings on this subject in the levels of graduation or post-graduation.

Keywords: Education. Postgraduate. Positivism. Epistemology. Business Administration.

\section{REFLEXIONANDO SOBRE LA OBJETIVIDAD: UNA EXPERIENCIA DIDÁCTICA SOBRE EL POSITIVISMO DE COMTE}

\section{RESUMEN}

El positivismo surgió como una de las primeras corrientes de pensamiento sistematizada reconocida como una epistemología en ciencias sociales. Se buscó sistematizar una forma de estudio de la epistemología positivista, propiciando un mejor aprovechamiento didáctico-pedagógico de los estudiantes. El estudio empírico se realizó a partir de un abordaje cualitativo, relatando una experiencia didáctica, en forma de taller, que sirvió como caso a ser estudiado, pues, en este ambiente, se puede interaccionar con doctorandos del curso de Administración. A través de este relato, se discutió sobre los principales conceptos de la epistemología positivista y se fornecieron insumos didácticos-pedagógicos aquellos que desean explorar encuentros sobre esta temática en los niveles de graduación o posgrado.

Palabras-clave: Enseñanza. Posgrado. Positivismo. Epistemología. Administración. 


\section{REFERÊNCIAS}

ABBRAGNANO, N. Dicionário de filosofia. São Paulo: Mestre Jou, 1970.

ABDALLA, M. M. et al. Quality in qualitative organizational research: types of triangulation as a methodological alternative. Administração: Ensino e Pesquisa, v. 19, n. 1, p. 66-98, 2018.

AZEVEDO, C. E. F. Positivismo no Brasil: o legado positivista no final do século XIX e uma análise dessa herança com base no binômio ruptura-continuidade de Bachelard e de Kuhn. In: IBEROAMERICAN ACADEMY CONFERENCE, 7., 2011, Lima. Anais... Lima: IAM, 2011.

AZEVEDO, C. E. F. et al. Administração: um campo de estudos positivista?. In: CONGRESSO DE ADMINISTRAÇÃO, SOCIEDADE E INOVAÇÃO, 1., 2011, Volta Redonda. Anais... Volta Redonda: UFF, 2011.

BACHELARD, G. A formação do espírito científico: contribuições para uma psicanálise do conhecimento. 2. ed. Rio de Janeiro: Contraponto, 2005.

BUELENS, M. et al. Methodological issues in negotiation research: a state-of-the-art-review. Group Decision and Negotiation, v. 17, n. 4, p. 321-345, 2008.

CARVALHO, J. L. F.; DAVEL, E. Introdução: arte, administração e organizações se encontram ao correr do diálogo. O\&S - Organizações \& Sociedade, v. 12, n. 32, p. 81-92, 2005.

CHIZZOTTI, A. A pesquisa qualitativa em ciências humanas e sociais: evolução e desafios. Revista Portuguesa de Educação, v. 16, n. 2, p. 221-236, 2003.

COMTE, A. Curso de filosofia positiva: discurso sobre o espírito positivo: discurso preliminar sobre o conjunto do positivismo: catecismo positivista. São Paulo: Abril Cultural, 1978.
COSTA, F. J.; RAMOS, R. R. (Eds.). O cinema pensa os negócios e os negócios o cinema: cinema, educação em negócios e pensamento crítico. Lisboa: Novas Edições Acadêmicas, 2015.

COSTA, M. C. C. Sociologia: introdução à ciência da sociedade. São Paulo: Moderna, 2005.

DALMORO, M. et al. Dominância epistemológica em estudos do campo: são ainda os administradores positivistas? In: ENCONTRO NACIONAL DA ANPAD, 31., 2007, Rio de Janeiro. Anais... Rio de Janeiro: Anpad, 2007.

DAVEL, E.; VERGARA, S. C.; GHADIRI, D. P. Administração com Arte: experiências vividas de ensino e aprendizagem. São Paulo: Atlas, 2007.

DELlaGNELO, E. H. L.; SILVA, R. C. Análise de conteúdo e sua aplicação em pesquisa na administração. In: VIEIRA, M. M. F.; ZOUAIN, D. M. (Orgs.). Pesquisa qualitativa em administração. Rio de Janeiro: FGV, 2005.

GIANNOTTI, J. A. Augusto Comte: vida e obra. In: H. TRINDADE. (Org.). O positivismo: teoria e prática: sesquicentenário da morte de Augusto Comte. Porto Alegre, UFRGS/ Unesco, 2007. p.19-30.

GRIMMER, M.; HANSON, D. The mix of qualitative and quantitative research in major marketing journals, 1993-2002. European Journal of Marketing, v. 41, n. 1/2, p. 58-70, 2007.

JAPIASSU, H. Introdução ao pensamento epistemológico. 7. ed. Rio de Janeiro: Livraria Francisco Alves, 1992.

JOHNSON, P.; DUBERLEY, J. Positivism: the management mainstream? In: Understanding management research: an introduction to epistemology. London: Sage, 2000.

KELLEY, J. C.; CLARCKSON, S. J. Recession Proof. New York: FOX, 2011. 1 Filme-vídeo 
(44 min.), son., color. J. C. Kelley, prod., S. J. Clarckson, dir. House, $7^{\text {th }}$ season, $14^{\text {th }}$ episode.

KUHN, T. S. A estrutura das revoluções científicas. 8. ed. São Paulo: Perspectiva, 2003.

LINS, I. História do Positivismo no Brasil. 2. ed. São Paulo: Companhia Editora Nacional, 1964.

MACHADO, D. Q.; MATOS, F. R. N. (Orgs.). Estudos observacionais em linguagem fílmica. Curitiba: CRV, 2012.

MACHADO, D. Q.; MATOS, F. R. N.; PINHEIRO, L. V. S. Barreiras ao pensamento e ao conhecimento científico: um debate sobre os ídolos do intelecto de Francis Bacon e os obstáculos epistemológicos de Gaston Bachelard. Contextus - Revista Contemporânea de Economia e Gestão, v. 11, n. 1, p. 39-49, jan./ jun. 2013.

MATTOS, P. L. C. L. Os resultados de minha pesquisa qualitativa não podem ser generalizados: pondo os pingos nos is dessa ressalva. In: ENCONTRO NACIONAL DA ANPAD, 30., 2006, Salvador. Anais... Salvador: Anpad, 2006.

MERRIAM, S. B. Qualitative research and case study applications in education. San Francisco: Jossey-Bass, 1998.

MONTEIRO, L. A.; MUNHOZ, D.; BERTHOLINI, F. Bachelard e a epistemologia histórica: uma vivência sobre a formação do espírito científico. In: ENCONTRO NACIONAL DA ANPAD, 36., 2012, Rio de Janeiro. Anais... Rio de Janeiro: Anpad, 2012.

OLIVEIRA, B. R. B.; COSTA, C. S. R.; KOVACS, E. P. Lentes epistemológicas e metodológicas nas pesquisas brasileiras em administração estratégica: características e pressupostos norteadores. In: ENCONTRO DE ESTUDOS EM ESTRATÉGIA DA ANPAD, 5., 2011, Porto Alegre. Anais... Porto Alegre: Anpad, 2011.
RODRIGUES, S.; CARRIERI, A. A tradição anglosaxônica em estudos organizacionais brasileiros. RAC - Revista de Administração Contemporânea, v. 5, p. 81-102, 2001.

SANTOS, J. E.; SILVA, E. S. A música "Positivismo" de Noel Rosa e a construção de sentidos: um estudo semântico-enunciativo da diretividade argumentativa no processo de leitura. Almanaque CIFEFIL, v. 14, n. 2, p. 2275-2286, 2010.

TOTA, A. P. Cultura, política e modernidade em Noel Rosa. São Paulo em Perspectiva, v. 15, n. 3, p. 45-49, 2001.

VAlentiM, O. F. O Brasil e o Positivismo. Rio de Janeiro: Publit, 2010.

VERGARA, S. C. Teoria prática educacional: da técnica à ética. PUC Ciência, v. 5, p. 12-20, 1990.

VERGARA, S. C.; CARVALHO, J. L. F. A fenomenologia e a pesquisa dos espaços de serviços. RAE - Revista de Administração de Empresas, v. 42, n. 3, p. 78-91, 2002. 